\title{
Coordination Contracts for Two-Echelon Supply Chain with Price-and-Carbon-Emission Dependent Demand
}

\section{Lu Li}

School of Business and Administration, South China University of Technology, Guangzhou, China

Email: stellar_lilu@outlook.com

Received 8 April 2016; accepted 15 May 2016; published 18 May 2016

Copyright (C) 2016 by author and Scientific Research Publishing Inc. This work is licensed under the Creative Commons Attribution International License (CC BY). http://creativecommons.org/licenses/by/4.0/

\section{c) (i) Open Access}

\begin{abstract}
As consumers' demand for low carbon products is growing, we develop a two-echelon supply chain with price-and-carbon-emission dependent demand consists of a dominant manufacturer and a retailer, and compare the optimal price and carbon emission and profit under the centralized and decentralized scenarios. Based on the manufacturer who wants to coordinate the whole supply chain, two different coordination contracts are proposed. We find that these two contracts not only improve profits of both sides, but also have the effect of carbon reduction. Finally we validate the effectiveness and environmental of these contracts through numerical examples.
\end{abstract}

\section{Keywords}

Demand, Price, Carbon Emission, Coordination Contract

\section{Introduction}

In recent decades, increasingly serious global warming has affected all aspects of human life, even the survival of human being. The work to reduce the emissions of greenhouse gases, most of which is carbon dioxide, has risen to be a common sense of all the word, and it has brought people more green life concept. This concept has affected people's daily lives_-people are willing to buy more environmental friendly products, which means that the demand for certain products will be affected by this product's environmental performance. Much research also confirmed that. For example Kleindorfer et al. (2005) and Sarkis et al. (2011) found that customers will continue to exert influence on companies to reduce the impact on the environment during production [1] [2]. 
Kassinis and Soterious (2003) found that if the customers doubt the products' environmentally performance, the demand of this kind product will reduce [3]. And Klassen et al. (1996), Elsayed et al. (2005) found that if manufactures reduce the impact of their products on environmental or improve the environmental performance of their products will increase their market share [4] [5]. Thus we can predict that with the more widespread awareness of environmental protection and enhanced in the future, the performance of the impact on environmental will affect the market demand in a more prominent way. Therefore, considering the demand influenced by product's environmental performance, when coordinated supply chain, will be an inevitable trend.

Currently, there are many scholars carry out the researches on the coordination of two-echelon supply chain with manufacturers and retailers. Wang et al. (2004) constructed a two-stage sales model, and applied the revenue sharing contract to coordinate the profit of two parties [6]. Raju and Zhang (2005) considered two-echelon supply chain model with a leading retailer, and studied how the parties collaborate for more benefit in the supply chain [7]. While Xie and Wei (2009) obtained optimal equilibrium price collaboration and cooperative advertising strategy by coordinating manufacturers and retailers [8]. Ouardighi and Kim (2010) constructed a supply chain with a vendor and two competing manufacturers who compete on price and product quality, and compared the supply chain coordination between the wholesale discount and revenue sharing contract [9]. Du et al. (2011) consider wholesale price discounts and credit contractual options to achieve supply chain coordination [10].

In the existing studies of supply chain coordination, the patterns of demand are different. Zhou et al. (2008) concerned on the demand depends on the inventory levels [11]; Chauhan (2005) considers the demand influenced by the price of the product [12]. While Yang and Zhou (2006) studied this case by the demand affected by pricing among competitors [13]. And Parthasarathi et al. (2011) did this research under the demand depend on pricing and the retailers' initial inventory levels at the same time [14]. However, in existing research, fewer papers consider carbon emission when they express the demand. In this article, therefore, we are considering demand depends on product sales prices and carbon emissions to study the supply chain coordination problem.

Reviewed the existing research of the coordination of supply chain, we found that the directions of the research are mainly wholesale price discount contract, revenue sharing contract, buyback contracts and credit contractual options. In this paper, the wholesale price with quantity discount contract and wholesale price are both used to coordinated the supply chain, by determining the reasonable wholesale price range and the amount of the discount, to achieve supply chain coordination, so that manufacturer and retailer got profits improved.

\section{Fundamental Assumptions}

We study a two-echelon supply chain coordination problem, with a dominated manufacturer and a retailer, both of the manufacturer and retailer make their decision base on the of maximization of their profits. The manufacturer sell a single product to retailer by the price of $w$, while the retailer sell their products to customers at price $p$.

The market demand of retailer not only depends on the price $p$, but also sensitive to the carbon emissions per unit of product. That requires to set a joint demand function with price and carbon emissions per unit of product, and the demand is monotonically decreasing at product price and carbon emissions per unit of product. Therefore we set the demand function as: the same as Yalabik et al. (2011) [15], $D(p, g)=a-b p-k g$. In this function, $p$ is the per-unit price charged by the firm and $g$ is the amount of emissions per unit of output produced. The parameters $a, b$, and $k$ are properties of the consumer market as follows: $a$ is the market size, $b$ is the sensitivity of the market to the firm's price, and $k$ is the sensitivity of the market to the firm's emissions.

At the same time, we assume that the manufacturer's initial unit product emissions amount is $g_{0}$, the fixed production cost of per unit product is $c$, the manufacturer is able to carbon emissions per unit of product $g$ by means of technology transformation, and the transformation cost is $t\left(g_{0}-g\right)^{2},(t>0)$ decide the size of the cost.

Despite the growing awareness of environmental protection, compared to the price, the impact of carbon emission on product demand is still much smaller. In addition, the cost of reducing carbon emissions and the transformation is also very impressive. Therefore, we assume that the parameter $b, k$ and $t$ satisfy $4 b t-k^{2}>0$, make it more convenient for the following discussion .

\section{Mathematical Formation and Analysis of the Model}

\subsection{Centralized Decision Model}

Under centralized decision, the manufacturer and the retailer will form a unified one, its purpose is to maximize the benefits of the whole supply chain, which is mainly achieved through the supply chain coordination and co- 
operation. In this paper, the centralized decision model of two-echelon supply chain is to maximize the profit of the whole supply chain, and it is necessary to make the sales price $p$ and the unit product carbon emissions $g$. In this case, this decision is the global optimal one, and provides the benchmark for the coordination of the manufacturer and retailer in the decentralized decision. So in the case of centralized scenario, the entire supply chain profit function is $\pi_{c}$ :

$$
\pi_{c}=(p-c)(a-b p-k g)-t\left(g_{0}-g\right)^{2}
$$

Take the partial derivative of the formula (1) for $p$ and $g$ respectively and make them equal to zero:

$$
\begin{gathered}
\frac{\partial \pi_{c}}{\partial p}=a+b c-2 b p-k g=0 \\
\frac{\partial \pi_{c}}{\partial g}=k c+2 t g_{0}-k p-2 t g=0
\end{gathered}
$$

Simultaneous (2) and (3) and solved, we get:

$$
\begin{gathered}
p_{I}^{*}=\frac{2 a t+2 b c t-c k^{2}-2 k t g_{0}}{4 b t-k^{2}} \\
g_{I}^{*}=\frac{4 b t g_{0}+b c k-a k}{4 b t-k^{2}}
\end{gathered}
$$

Put the formula (4) and (5) into the demand function, we get:

$$
D_{I}^{*}=\frac{2 b t\left(a-b c-k g_{0}\right)}{4 b t-k^{2}}
$$

The optimal profit of supply chain under centralized scenario is:

$$
\pi_{c}^{*}=\frac{t\left(4 b t-k^{2}\right)\left(a-b c-k g_{0}\right)^{2}}{\left(4 b t-k^{2}\right)^{2}}
$$

Theorem 1. There exist optimal $p_{I}^{*}$ and $g_{I}^{*}$ to maximize the profit of supply chain.

\subsection{Decentralized Decision Model}

In the case of decentralized scenario, manufacturer and retailer make their decisions to maximize their own profits, the profit of the retailer $\pi_{r}$ and manufacturer $\pi_{m}$ are:

$$
\begin{gathered}
\pi_{r}=(p-w)(a-b p-k g) \\
\pi_{m}=(w-c)(a-b p-k g)-t\left(g_{0}-g\right)^{2}
\end{gathered}
$$

Based on Stackelberg principle, we simultaneous (8) and (9), and solve, we get:

$$
\begin{gathered}
w_{N}^{*}=\frac{4 a t+4 b c t-c k^{2}-4 k t g_{0}}{8 b t-k^{2}} \\
g_{N}^{*}=\frac{8 b t g_{0}+b c k-a k}{8 b t-k^{2}} \\
p_{N}^{*}=\frac{6 a t+2 b c t-c k^{2}-6 k t g_{0}}{8 b t-k^{2}}
\end{gathered}
$$

Put the formula (11) and (12) into the demand function, we get:

$$
D_{N}^{*}=\frac{2 b t\left(a-b c-k g_{0}\right)}{8 b t-k^{2}}
$$

Theorem 2. The demand under decentralized scenario is smaller than the one under centralized scenario. 
Also, with the formula above, we get the optimal profit of manufacture, retailer and the whole supply chain:

$$
\begin{gathered}
\pi_{m}^{*}=\frac{t\left(8 b t-k^{2}\right)\left(a-b c-k g_{0}\right)^{2}}{\left(8 b t-k^{2}\right)^{2}} \\
\pi_{r}^{*}=\frac{4 b t^{2}\left(a-b c-k g_{0}\right)^{2}}{\left(8 b t-k^{2}\right)^{2}} \\
\pi_{r}^{*}+\pi_{m}^{*}=\frac{t\left(12 b t-k^{2}\right)\left(a-b c-k g_{0}\right)^{2}}{(8 b t-k)^{2}}
\end{gathered}
$$

The margin profit in of the supply chain between centralized scenario and decentralized scenario is:

$$
\Delta \pi_{c}=\pi_{c}^{*}-\left(\pi_{r}^{*}+\pi_{m}^{*}\right)=\frac{16 b^{2} t^{3}\left(a-b c-k g_{0}\right)^{2}}{\left(4 b t-k^{2}\right)\left(8 b t-k^{2}\right)^{2}}
$$

Theorem 3. The profit of the supply chain under centralized scenario is bigger than the one decentralized scenario.

We can find that, $p_{I}^{*}<p_{N}^{*}, g_{I}^{*}<g_{N}^{*}$ and $D_{I}^{*}>D_{N}^{*}$, which mean under centralized scenario the price and emissions per unit of output produced is lower, and it accepts more customers than the decentralized scenario. Not only it is good for environment, but also it can bring more profit.

So, we want to coordinate the whole supply chain, base on the centralized scenario. Therefore, how to motivate the manufacturer and retailer make their decision throughout the supply chain profit maximization, how to effectively design coordination mechanism and implementation is crucial

\section{Coordination Contracts}

Manufacturer and retailer coordinate with each other is to maximize the supply chain profits, but at the same time, under coordination contracts the profits of manufacturer and retailer is not less than the profit they get under decentralized scenario. That means they all attain Pareto optimal. We mainly determine a reasonable wholesale price and quantity discount of wholesale price contract to reach the coordination.

\subsection{Wholesale Price Contract}

In this case, the manufacturer develops a reasonable wholesale price to sell products to retailers, and the price and the emissions per unit of output produced are the same with centralized scenario, while their own profits are not less than the profits under decentralized scenario, Assume the wholesale price manufacturers gives is $w$, then the profit of retailer and manufacturer are:

$$
\begin{gathered}
\pi_{r 1}=\left(p_{I}^{*}-w\right) D_{I}^{*} \\
\pi_{m 1}=(w-c) D_{I}^{*}-t\left(g_{0}-g_{I}^{*}\right)^{2}
\end{gathered}
$$

Theorem 4. When the wholesale price $w$ is with $\left(w_{\min }, w_{\max }\right)$, both the manufacturer and retailer would get profits not less than the decentralized scenario one. While the

$$
w_{\min }=\frac{\pi_{m}^{*}+t\left(g_{0}-g_{I}^{*}\right)^{2}+c D_{I}^{*}}{D_{I}^{*}}, \quad w_{\max }=\frac{p_{I}^{*} D_{I}^{*}-\pi_{I}^{*}}{D_{I}^{*}}
$$

It's easy to prove the theorem 4, from the assumptions above, we know

$$
\pi_{r 1} \geq \pi_{r}^{*}, \quad \pi_{m 1} \geq \pi_{m}^{*}
$$

That are $\left(p_{I}^{*}-w\right) D_{I}^{*} \geq \pi_{r}^{*},(w-c) D_{I}^{*}-t\left(g_{0}-g_{I}^{*}\right)^{2} \geq \pi_{m}^{*}$ 
Then we get $w \geq \frac{\pi_{m}^{*}+t\left(g_{0}-g_{I}^{*}\right)^{2}+c D_{I}^{*}}{D_{I}^{*}}, w \leq \frac{p_{I}^{*} D_{I}^{*}-\pi_{r}^{*}}{D_{I}^{*}}$

Finally, $w_{\min }=\frac{\pi_{m}^{*}+t\left(g_{0}-g_{I}^{*}\right)^{2}+c D_{I}^{*}}{D_{I}^{*}}$

$$
w_{\max }=\frac{p_{I}^{*} D_{I}^{*}-\pi_{r}^{*}}{D_{I}^{*}}, \quad w_{\max }-w_{\min }=\frac{\Delta \pi_{c}}{D_{I}}>0
$$

When $w \in\left(w_{\min }, w_{\max }\right)$, the profit of this case is equal to the centralized scenario, compare with decentralized scenario we can get the increased profit of manufacturer and retailer .

1) The increased profit of supply chain: $\Delta \pi_{c}=\left(w_{\max }-w_{\min }\right) D_{I}^{*}>0$

2) The increased profit of retailer: $\Delta \pi_{r 1}=\left(w_{\max }-w\right) D_{I}^{*} \geq 0$

3) The increased profit of manufacturer: $\Delta \pi_{m 1}=\left(w-w_{\min }\right) D_{I}^{*} \geq 0$

When $w=w_{\max }$, the increased profit of retailer and manufacturer are 0 and $\Delta \pi_{c}$.

When $w=w_{\min }$, the increased profit of retailer and manufacturer are $\Delta \pi_{c}$ and 0.

\subsection{Wholesale Price Discount Contract}

Manufacturers and retailers make the decision to maximize the profit of the supply chain the demand will also, as we can know for $n$ the formula $D_{I}^{*}>D_{N}^{*}$, increased. So for the cooperation of retailer, we can make a wholesale price discount if the demand of retailer is bigger than $D_{N}^{*}$, then the part of $D_{N}^{*}$ is sell to retailer at price $w$, while the part above $D_{N}^{*}$ will get a discount $\partial$. The profit of the retailer $\pi_{r 2}$ and the manufacturer $\pi_{m 2}$ are respectively:

$$
\begin{gathered}
\pi_{r 2}=\left(p_{I}^{*}-w\right) D_{N}^{*}+\left(p_{I}^{*}-\partial w\right)\left(D_{I}^{*}-D_{N}^{*}\right) \\
\pi_{m 2}=(w-c) D_{N}^{*}+(\partial w-c)\left(D_{I}^{*}-D_{N}^{*}\right)-t\left(g_{0}-g_{I}^{*}\right)^{2}
\end{gathered}
$$

Theorem 5. When the wholesale price discount $\partial$ is with $\left(\partial_{\min }, \partial_{\max }\right)$, both the manufacturer and retailer would get profits not less than the decentralized scenario one. While the

$$
\partial_{\min }=\frac{\pi_{m}^{*}+t\left(g_{0}-g_{I}^{*}\right)^{2}+c D_{I}^{*}-w D_{N}^{*}}{w\left(D_{I}^{*}-D_{N}^{*}\right)}, \partial_{\max }=\frac{p_{I}^{*} D_{I}^{*}-w D_{N}^{*}-\pi_{r}^{*}}{w\left(D_{I}^{*}-D_{N}^{*}\right)}
$$

When $\partial \in\left(\partial_{\min }, \partial_{\max }\right)$, the profit of this case is equal to the centralized scenario, compare with decentralized scenario we can get the increased profit of manufacturer and retailer .

1) The increased profit of supply chain: $\Delta \pi_{c}=\left(\partial_{\max }-\partial_{\min }\right) w\left(D_{I}^{*}-D_{N}^{*}\right)>0$

2) The increased profit of retailer: $\Delta \pi_{\mathrm{r} 2}=\left(\partial_{\max }-\partial\right) w\left(D_{I}^{*}-D_{N}^{*}\right) \geq 0$

3) The increased profit of manufacturer: $\Delta \pi_{m 2}=\left(\partial-\partial_{\min }\right) w\left(D_{I}^{*}-D_{N}^{*}\right) \geq 0$

When $\partial=\partial_{\max }$, the increased profit of retailer and manufacturer are 0 and $\Delta \pi_{c}$.

When $\partial=\partial_{\min }$, the increased profit of retailer and manufacturer are $\Delta \pi_{c}$ and 0 .

\section{Numerical Examples}

For a market whose total demand is 200, and $g_{0}=20, c=5$ the demand function is $D(p, g)=200-8 p-g$, the the transformation cost is $0.5(20-g)^{2}$, then we can get the following table.

From Table 1, we know that the profit and demand of centralized scenario is bigger than decentralized scenario, also the carbon emissions is smaller, that means under the centralized scenario, we can get a better emission reduction. So it's importany to use the contracts we design.

From Table 2, we know if the manufacture make the wholesale price unde the range of $(9.30,12.15)$, the profit of the whole supply chain, retailer and manufacturer will improve. If the wholesale price is 13 , the discount will give to the part of $\left(D_{I}^{*}-D_{N}^{*}\right)=38.53764$. Also it will decrease the carbon emission. 
Table 1. The results under centralized scenario and decentralized scenario.

\begin{tabular}{|c|c|c|c|c|c|c|c|c|c|}
\hline \multicolumn{5}{|c|}{ Centralized scenario } & \multicolumn{5}{|c|}{ Decentralized scenario } \\
\hline$p_{I}^{*}$ & $g_{I}^{*}$ & $D_{I}^{*}$ & $\pi_{c}$ & $p_{N}^{*}$ & $g_{N}^{*}$ & $w_{N}^{*}$ & $D_{N}^{*}$ & $\pi_{r}^{*}$ & $\pi_{m}^{*}$ \\
\hline 14.33 & 10.67 & 74.67 & 653.33 & 18.55 & 15.48 & 14.03 & 36.13 & 163.16 & 316.13 \\
\hline
\end{tabular}

Table 2. The results of different contracts

\begin{tabular}{|c|c|c|c|c|}
\hline Contracts & Profit of chain & Profit of retailer & Profit of manufacturer & Parameter range \\
\hline Wholesale price & 653.33 & $(163.16,337.20)$ & $(316.13,490.17)$ & $\begin{array}{c}\left(w_{\min }, w_{\max }\right) \\
(9.30,12.15)\end{array}$ \\
\hline Wholesale price discount & 653.33 & $(163.16,337.20)$ & $(316.129,490.17)$ & $\begin{array}{l}\text { When } w=13 \\
\left(\partial_{\min }, \partial_{\max }\right) \\
(0.53,0.87)\end{array}$ \\
\hline
\end{tabular}

\section{Conclusions}

With the popularity of green life, the demand for green products is being more intense. Based on this, we consider the impact of price and carbon emissions on demand, and coordination of two-echelon supply chain. The profit realized by centralized scenario is bigger than decentralized scenario, and the carbon emission is lower. To coordinate the supply chain and improve the profit of both manufacturer and retailer, we design two contracts; within the range we give, we can achieve our goals. For a more green production, it is important to use this kind of contract.

Also, there are limitations of this research. The most important is we do not give specific contracts, including the contract of wholesale price and contract of wholesale price discount, but, to a certain extent, the result of this paper provides effective suggestions.

\section{References}

[1] Kleindorfer, P.R., Singhal, K. and Van Wassenhove, L.N. (2005) Sustainable Operations Management. Production and Operations Management, 14, 482-492. http://dx.doi.org/10.1111/j.1937-5956.2005.tb00235.X

[2] Sarkis, J., Zhu, Q. and Lai, K. (2011) An Organizational Theoretic Review of Green Supply Chain Management Literature. International Journal of Production Economics, 130, 1-15. http://dx.doi.org/10.1016/j.ijpe.2010.11.010

[3] Kassinis, G. and Soteriou, A. (2003) Greening the Service-Profit Chain: The Impact of Environmental Management Practices. Production and Operations Management, 12, 386-403. http://dx.doi.org/10.1111/j.1937-5956.2003.tb00210.x

[4] Klassen, R.D. and McLaughlin, C.P. (1996) The Impact of Environmental Management on Firm Performance. Management Science, 42, 1199-1214. http://dx.doi.org/10.1287/mnsc.42.8.1199

[5] Elsayed, K. and Paton, D. (2005) The Impact of Environmental Performance on Firm Performance: Static and Dynamic Panel Data Evidence. Structural Change and Economic Dynamics, 16, 395-412. http://dx.doi.org/10.1016/j.strueco.2004.04.004

[6] Wang, Y., Jiang, L. and Shen, Z.J. (2004) Channel Performance under Consignment Contract with Revenue Sharing. Management Science, 50, 34-47. http://dx.doi.org/10.1287/mnsc.1030.0168

[7] Raju, J. and Zhang, Z.J. (2005) Channel Coordination in the Presence of a Dominant Retailer. Marketing Science, 24, 254-262. http://dx.doi.org/10.1287/mksc.1040.0081

[8] Xie, J.X. and Wei, J.C. (2009) Coordinating Advertising and Pricing in a Manufacturer-Retailer Channel. European Journal of Operational Research , 197, 785-791. http://dx.doi.org/10.1016/j.ejor.2008.07.014

[9] Ouardighi, E. and Kim, F.B. (2010) Supply Quality Management with Wholesale Price and Revenue-Sharing Contracts under Horizontal Competition. European Journal of Operational Research, 206, 329-340. http://dx.doi.org/10.1016/j.ejor.2010.02.035

[10] Du, R., Banerjee, A. and Kim, S.L. (2013) Coordination of Two-Echelon Supply Chains Using Wholesale Price Discount and Credit Option. International Journal of Production Economics, 143, 327-334. http://dx.doi.org/10.1016/j.ijpe.2011.12.017

[11] Zhou, Y.W., Min, J. and Suresh, K.G. (2008) Supply-Chain Coordination under an Inventory-Level-Dependent De- 
mand rate. International Journal of Production Economics, 113, 518-527. http://dx.doi.org/10.1016/j.ijpe.2007.10.024

[12] Chauhan, S.S. and Marie, J.P. (2005) Analysis of a Supply Chain Partnership with Revenue Sharing. International Journal of Production Economics, 97, 44-51. http://dx.doi.org/10.1016/j.ijpe.2004.05.006

[13] Yang, S.L. and Zhou, Y.W. (2006) Two-Echelon Supply Chain Models: Considering duopolistic Retailers’ Different Competitive Behaviors. International Journal of Production Economics, 103, 104-116.

[14] Parthasarathi, G., Sarmah, S.P. and Jenamani, M. (2011) Supply Chain Coordination under Retail Competition Using Stock Dependent Price-Setting Newsvendor Framework. Operational Research, 11, 259-279.

[15] Yalabik, B. and Fairchild, R.J. (2011) Customer, Regulatory, and Competitive Pressure as Drivers of Environmental Innovation. International Journal of Production Economics, 131, 519-527. http://dx.doi.org/10.1016/j.ijpe.2011.01.020 